\title{
Heat coupling of the pan-European vs. regional electrical grid with excess renewable energy
}

\author{
Asad Ashfaq ${ }^{\mathrm{a}, \mathrm{b}, *}$, Zulqarnain Haider Kamali, ${ }^{\mathrm{c}}$, Mujtaba Hassan Agha ${ }^{\mathrm{d}}$, Hirra Arshid ${ }^{\mathrm{e}}$ \\ ${ }^{a}$ Chair of Decentralized Energy Systems and Storage Technologies, Brandenburg University of Technology Cottbus - \\ Senftenberg, 03046 Cottbus, Germany \\ ${ }^{b}$ Department of Engineering, Aarhus University, 8000 Aarhus C, Denmark \\ ${ }^{c}$ Department of Electrical and Computer Engineering, University of Massachusetts-Lowell, 01854 MA, United States \\ ${ }^{d}$ Department of Mechanical Engineering, Capital University of Science and Technology, 44000 Islamabad, Pakistan \\ ${ }^{e}$ Department of Engineering Management, National University of Science and Technology, 44000 Islamabad, Pakistan
}

\begin{abstract}
The feasibility of heating sector integration into future highly renewable electrical grid is examined for a regional and pan-European network. A novel geographical weather dependent model for calculating the heat demand using a temporal resolution of an hour with a spatial resolution of $40 \times 40 \mathrm{~km}^{2}$ and an optimized solution for the utilization of excess renewable generation with least energy needs is presented. Heating sector is modeled and coupled separately with two different heat coupling models, heat-pump coupling and electric-resistance coupling, both having heat-storage and gas-boiler. Results show coupling with the regional network requires least heat-storage capacity and coupling with an individual country network requires the least gas-boiler capacity. However, coupling with the pan-European network results in least balancing energy needs. It is found that heat-pump coupling provides more benefit than the electric-resistance coupling, with 4 times more heat-storage energy and $38 \%$ less requirement for the gas-boiler energy. Optimum energy mix between the heat-storage energy and gas-boiler energy suggests that the present amount of excess generation is not enough to fully support the heating sector, but if the renewable energy generation is increased by $50 \%$ then heat-storage will play an important role.
\end{abstract}

Keywords: Renewable energy; excess generation; heat pump; heat coupling; heat storage; district heating.

\section{Introduction}

With recent environmental and health concerns, there is an immense increase in the integration of decentralized generation into the electrical grid. In 2009, the European Union (EU) set an ambitious target of achieving an $80 \%$ reduction in greenhouse gas (GHG) emissions by the year 2050 from the level recorded in 51990 [1]. In the recent report titled 'energy roadmap 2050', the EU has proposed six different strategies which focus on the electrification of the heating sector [2]. Furthermore, several researchers have suggested that it

${ }^{*}$ Corresponding author. Address: Chair of Decentralized Energy Systems and Storage Technologies, Brandenburg University of Technology Cottbus - Senftenberg, 03046 Cottbus, Germany

Email address: asad_ashfaq2000@yahoo.com (Asad Ashfaq) 


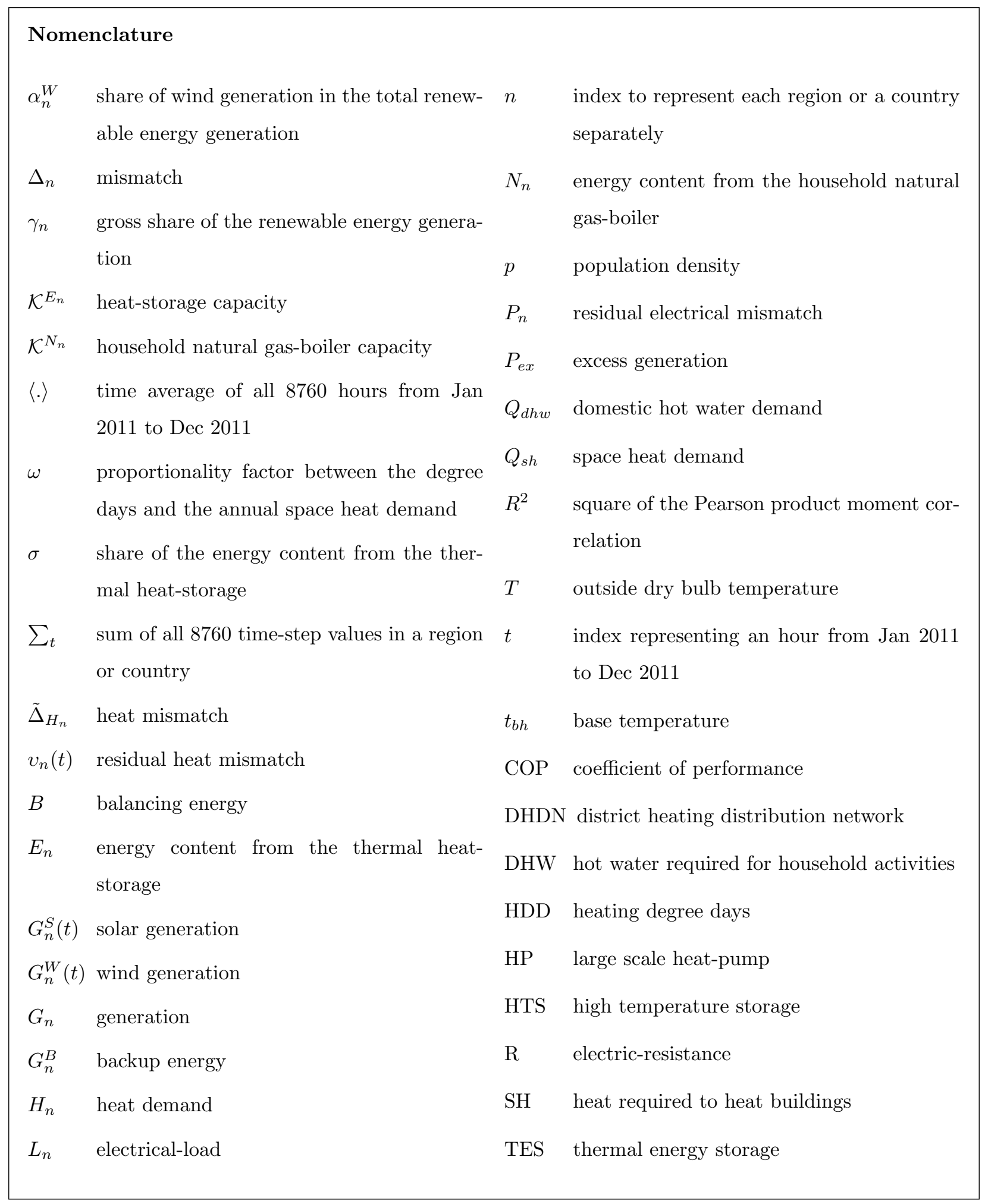

is feasible to fulfill $100 \%$ energy requirements using renewable resources. Delucchi et al. [3] and Jacabson et al. 4] proposed the possibility of providing all energy using wind, water and solar power, Lund et al. 
[5] and Connolly et al. 6] discussed 100\% renewable energy systems for Denmark and Ireland respectively. Glasnovic et al. [7] and Lund et al. 8] have provided the vision of renewable energy as a source of electric power for sustainable development.

Wind and solar electrical generation have dominated other renewable generation sources and their cost effectiveness is already comparable to fossil fuels [4. However, the dependence of wind and solar generation on weather makes the electrical grid vulnerable to power outages and shortages. Recent studies have found that for higher penetration of renewable electricity systems, it is more economical to have excess generation rather than using electrical storage [9] or generating according to the demand [10. The coupling of the heating sector with excess generation for the cost optimum operation is recommended in [11, 12, but technical feasibility for the secure operation of the European energy network is still unknown and the main objective of this study.

In this paper the feasibility and an optimum strategy for the coupling of heating sector with pan-European and regional network is discussed. Previously, Budischak et al. 13 and Pensini et al. 14 have concluded that the heat coupling systems are both technically and economically feasible for the US electrical grid and utilization of excess renewable generation in such system not only leads to reduction in the electrical storage but also to a decrease in the cost of electricity generation.

However, limited knowledge is available on the European electrical grid from this aspect. Bossmann et al. 15. has calculated the potential of electric heating systems for the integration of renewable energy sources and found it to be relatively higher for the United Kingdom than for Germany and France. Bach et al. [16] and Ommen et al. [17, has discussed the technical and private economic aspects of the integration of large scale heat pumps and lowering the district heating temperature. Lund [18 has identified electric heating conversion as central solution for achieving $\mathrm{CO}^{2}$ reduction targets in Denmark and Thellufsen et al. [19], has recommended the benefit of coordinating savings from the synergies of the electricity and district heating sector. The potential benefits of a strong renewable friendly policies for a German heating market have been estimated by Bauermann [20] and the large scale implementation of district heating system for 30 European countries by Persson et al. 21. But there are still several unanswered questions:

- how our will network behave after integrating different heat coupling model variants?

- how variation in the wind and solar mix $(\alpha)$ and renewable energy generation $(\gamma)$ will affect our network?

- how much heat-storage energy and gas-boiler energy will be required?

- will a connected pan-European electrical network affect the required heat-storage capacity and gasboiler capacity?

This study answer these questions by using the same heat coupling models as used by Pensini et al. 14] and investigates how different networks will respond to fluctuating weather patterns. For this purpose, historical weather and energy consumption data is used with a temporal resolution of an hour and a spatial resolution of $40 \times 40 \mathrm{~km}^{2}$. Furthermore, all parameters and technological constraints have been normalized 
with respect to electrical-load and heat demand requirements making these results more robust, practical for long term analysis and usable for pricing schemes of future networks. The use of such weather based modeling is well-established and has been used for several important findings such as;

- determining an optimal mix between the wind and solar generation [22, 23].

- identifying electrical grid storage needs [9, 24].

- impact of transition to a pan-European renewable electrical grid [11, 25 27].

- feasibility of interconnected fully renewable US electrical grid [12, 28],

- calculating backup flexibility in large-scale renewable systems [29].

In this study, two different variants of the heat coupling models have been investigated: heat-pump coupling and electric-resistance coupling. Besides the method of heat conversion, the major difference between these two models is the presence of district heating distribution network. Heat-pump coupling model assumes a centralize heat-storage, which is integrated into the already present district heating distribution network. Any excess heat is stored in the centralize heat-storage and heat is provided when required by the customers. While, electric-resistance model does not have a centralize heat-storage. Excess generation is delivered directly to the consumers and stored in an on-site heat-storage.

The paper will proceed as follows: the methodology for electrical grid and heating sector modeling is explained in section 2.2 and 2.3 respectively. Subsequently, the geographical weather dependent model for calculating the heat demand and heat coupling models is introduced in section 2.4 and 2.5. It is assumed, that each region and country has its own heat coupling and they can share their heat-storage energy and gas-boiler energy with each other. Then, in section 3 both heat coupling model are analyzed and compared for different networks and the optimum wind and solar mix for reduced backup energy, gas-boiler energy and heat-storage energy need is calculated. Finally, in section 3.4 the need for required heat-storage and gas-boiler capacity and the optimum energy mix between heat-storage and gas-boiler energy is discussed. The results are presented in section 4 and we discuss the strategy that is most suitable for the heat coupling.

\section{Methodology}

\subsection{Weather driven modeling}

This analysis is based on a robust weather driven modeling, where 35 years (1979-2013) of weather data is taken from NCEP(National Centers for Environmental Prediction)-CFSR(Climate Forecast System Reanalysis) [30, 31] and 8 years (2000-2007) of wind, solar generation and electrical-load time-series for 30 European countries is taken from Ref [22, 24, 32. Both of these historical data-sets have a temporal resolution of an hour and a spatial resolution of $40 \mathrm{x} 40 \mathrm{~km}^{2}$. Wind and solar are taken as renewable energy sources, as they constitute major share in the variable renewable energy sources. However, other energy 
sources (biomass, hydro, tidal and conventional generation) are assumed to be present for instantaneous or emergency backup purposes. Data for each country is collected by the sum of $40 \mathrm{x} 40 \mathrm{~km}^{2}$ regions and represented by a node $n$ and accumulation of $30 n$ nodes give a pan-European analysis. This method of modeling has been previously used for several findings in $[9,11,12,22,29$.

\subsection{Electrical grid modeling}

Calculating the mismatch $\Delta_{n}$ is central to this research. Mismatch $\Delta_{n}$ at a node $n$ is the difference between the electrical-load $L_{n}$ and the generation $G_{n}$ from wind $G_{n}^{W}(t)$ and solar $G_{n}^{S}(t)$ generation.

$$
\begin{gathered}
G_{n}(t)=G_{n}^{W}(t)+G_{n}^{S}(t) \\
\alpha_{n}^{W}=\frac{\left\langle G_{n}^{W}\right\rangle}{\left\langle G_{n}\right\rangle} \\
\gamma_{n}=\frac{\left\langle G_{n}\right\rangle}{\left\langle L_{n}\right\rangle} \\
\Delta_{n}=\gamma_{n}\left\langle L_{n}\right\rangle\left[\left(1-\alpha_{n}^{W}\right) \cdot G_{n}^{S}(t)+\alpha_{n}^{W} \cdot G_{n}^{W}(t)\right]-L_{n}(t)
\end{gathered}
$$

In the above expression, wind and solar generation at a node $n$ and time $t$ is first normalized to an average of unity and then scaled with the gross mean electrical-load $\left\langle L_{n}\right\rangle$. Here, the symbol $\langle$.$\rangle represents$ time average and $L_{n}$ is the electrical-load in MW at a node $n$ and time $t$. The share of wind generation in total renewable energy generation $G_{n}$ is defined by $\alpha_{n}^{W}$. The relative share of wind generation is denoted by $\alpha_{n}^{W} \cdot G_{n}^{W}$ and the corresponding share of solar generation is $\left(1-\alpha_{n}^{W}\right) \cdot G_{n}^{S}$. Renewable energy generation $\gamma_{n}$ is the gross share of renewable energy generation. It is a ratio between the average renewable energy generation and average electrical-load and used as a scaling factor to model the network with different gross share of renewable generation.

90 Excess generation $P_{e x}$ in a network is calculated from intervals where the mismatch is positive. Whereas, backup energy $G_{n}^{B}$ is calculated from intervals where the mismatch is negative. Backup energy $G_{n}^{B}$ is the energy deficit in a network and needs to be fulfilled by other energy sources.

$$
\begin{gathered}
P_{e x}(t)= \begin{cases}\left|\Delta_{n}(t)\right| & \text { if } \Delta_{n}(t) \geq 0, \\
0 & \text { otherwise. }\end{cases} \\
G_{n}^{B}(t)= \begin{cases}\left|\Delta_{n}(t)\right| & \text { if } \Delta_{n}(t) \leq 0, \\
0 & \text { otherwise. }\end{cases}
\end{gathered}
$$

The equation for residual electrical mismatch $P_{n}$ at specific node $n$ becomes

$$
P_{n}\left(\gamma_{n}, \alpha_{n} ; t\right)=\Delta_{n}\left(\gamma_{n}, \alpha_{n} ; t\right)+G_{n}^{B}(t)-P_{e x}(t)
$$




\subsection{Heating sector integration modeling}

Heat mismatch $\tilde{\Delta}_{H_{n}}$ plays an important role in the integration of the heating sector. Heating sector is modeled exactly in the same way as the electrical grid in 2.2 and the heat demand $H_{n}$ is normalized to the mean heat demand $\left\langle H_{n}\right\rangle$. Heat mismatch $\tilde{\Delta}_{H_{n}}$ at a node $n$ and hour $t$, is the difference between the excess generation $P_{e x}$ in an electrical grid and heat demand $H_{n}$. Using eq(7),

$$
\tilde{\Delta}_{H_{n}}\left(\gamma_{n}, \alpha_{n} ; t\right)=\Delta_{n}\left(\gamma_{n}, \alpha_{n} ; t\right)+G_{n}^{B}(t)-P_{e x}(t)+H_{n}(t)
$$

Heat mismatch $\tilde{\Delta}_{H_{n}}$ is negative for intervals where the network has excess heat and can be stored into the heat-storage $E_{n}$. Whereas, heat mismatch $\tilde{\Delta}_{H_{n}}$ is positive for intervals where the network has heat-deficit and the gas-boiler $N_{n}$ is to be used as backup heat.

$$
\begin{aligned}
& E_{n}(t)= \begin{cases}\left|\tilde{\Delta}_{H_{n}}(t)\right| & \text { if } \tilde{\Delta}_{H_{n}}(t) \leq 0, \\
0 & \text { otherwise. }\end{cases} \\
& N_{n}(t)= \begin{cases}\left|\tilde{\Delta}_{H_{n}}(t)\right| & \text { if } \tilde{\Delta}_{H_{n}}(t) \geq 0, \\
0 & \text { otherwise. }\end{cases}
\end{aligned}
$$

Residual heat mismatch $v_{n}(t)$ after the integration of heating sector at a node $n$ then becomes,

$$
v_{n}(t)=\tilde{\Delta}_{H_{n}}(t)+E_{n}(t)-N_{n}(t)
$$

(a)

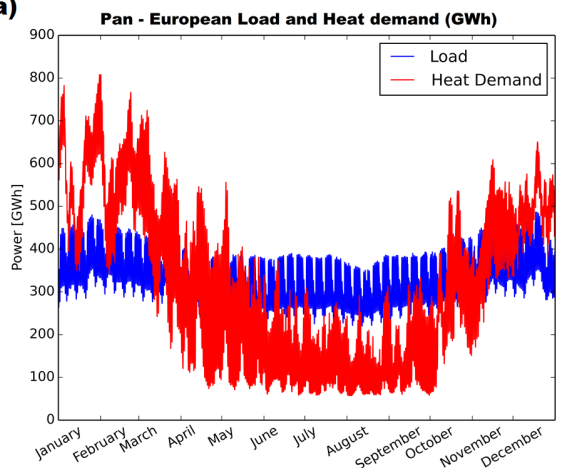

(b)

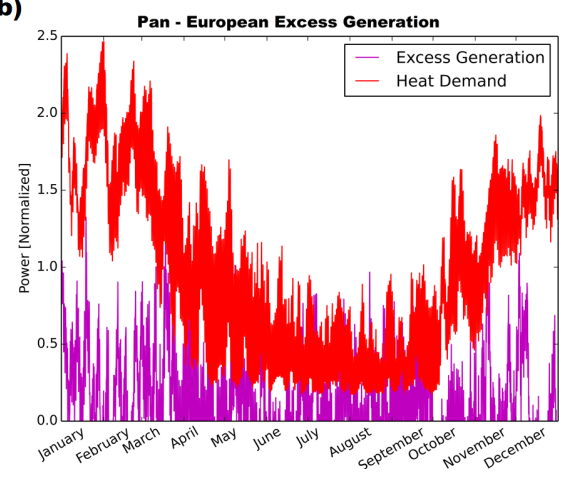

Figure 1: Seasonal pattern of electrical-load $L_{n}$, heat demand $H_{n}$ and excess generation $P_{e x}$ at an hourly resolution for a pan-European network. Fig (a) show electrical-load and heat demand and fig (b) show excess generation and heat demand. These seasonal patterns indicate similarity between the wind generation and heat demand, as both are higher in winter and lower in summer. Here, heat demand is normalized to the average heat demand and excess generation is normalized to the average electrical-load.

Backup energy $G_{n}^{B}$ and gas-boiler $N_{n}$ will collectively be called 'Balancing' $B_{n}$, as they balance the network. Before introducing the heat coupling models, we will introduce our geographical model which has been used for calculating the heat demand. 


\subsection{Geographical weather dependant heat demand model}

Unfortunately unlike the electricity sector, there are several small scale operators in the heating sector which limits the availability of heat demand data. There are few geographical models proposed for calculating the heat demand in [33 37, but none of these provide heat-demand time-series for an entire country or Europe.

$$
H_{n}(t)=Q_{s h}(t)+Q_{d h w}(t)
$$

Space heat demand is the heat required by buildings and is calculated by using 'degree-day method'. Whereas, water demand is the heat required for domestic purposes i.e. shower, washing etc and has been assumed to remain constant throughout the year.

In figure 2, it can be observed that few regions of Germany, the Netherlands and United Kingdom have more space heat demand than others. Even the northern part of Europe has more colder climate and temperature variations but the central Europe has greater space heat demand. Another conclusion that can be drawn that the central European countries have more heat losses than Nordic countries. This can be realized as our geographical model only uses temperature variations for calculating the space heat demand.

\subsubsection{Degree-day method}

Degree-day method is a commonly used to estimate space heat demand. Estimations are pretty close to the real heat demand as space heat demand $Q_{s h}$ depends on the outside temperature. This method has been used for several studies in 40 48, and compares the outside dry bulb temperature $T$ from the base temperature $t_{b h}$. Where, base temperature $t_{b h}$ is the temperature below which space heat is needed in the buildings.

Heating degree days (HDD) at a certain hour are calculated by subtracting the temperature $T$ of that hour from the base temperature $t_{b h}$ and if the temperature $T$ is above the base temperature $t_{b h}$ then the heating degree days are zero. Space heat demand $Q_{s h}$ is calculated by multiplying heating degree days (HDD) with the heat factor $\omega$. Heat factor $\omega$ is a ratio between the cumulative annual heating degree days (HDD) 
(a)

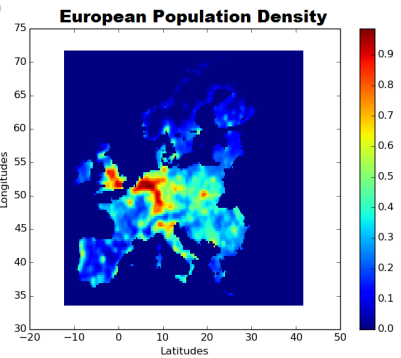

(c)

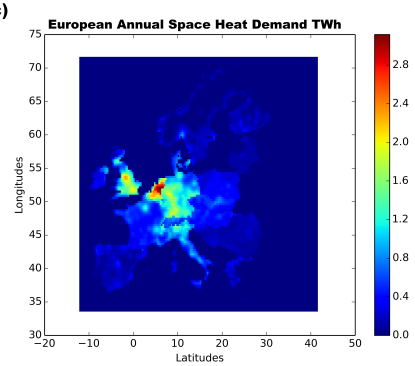

(b)

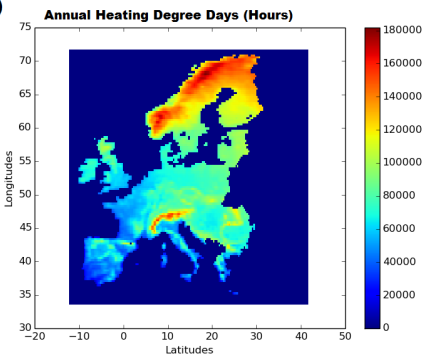

(d)

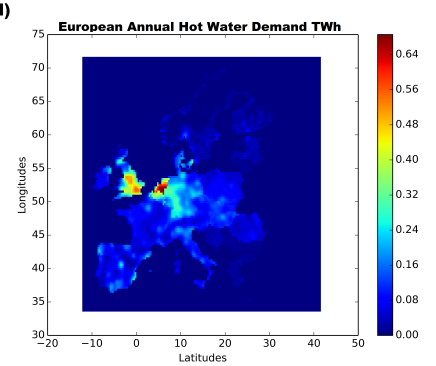

Figure 2: Results from the geographical heat demand calculation model, annual heat demand $H_{n}$ at a spatial resolution of $40 \mathrm{x}$ $40 \mathrm{~km}^{2}$ for the year (2011). Fig (a) show population density $p$ [normalized] and Fig (b) show cumulative annual heating degree days (hours) - onshore. Figs (c) and (d) show, the annual distribution of space heat demand $Q_{s h}$ and hot water demand $Q_{d h w}$ in different regions of Europe. (For interpretation of the references to color in this figure legend, the reader is adviced to refer to the web version of this article).

and annual space heat demand $Q_{s h_{\text {annual }}}$. It is taken from Ref [49, 50] and shown in fig 3 .

$$
\begin{gathered}
H D D(t)= \begin{cases}t_{b h}-|T| & \text { if }|T| \leq t_{b h}, \\
0 & \text { otherwise. }\end{cases} \\
Q_{s h_{\text {annual }}}=\omega \cdot p \cdot \sum_{t=1}^{8760} H D D(t) \\
\omega=\frac{Q_{s h_{\text {annual }}}}{p \cdot \sum_{t=1}^{8760} H D D(t)} \\
Q_{s h}(t)=p \cdot \omega \cdot H D D(t)
\end{gathered}
$$

It is important to realize, the reliability of heat demand estimation from the degree-day method depends upon the accuracy of temperature measurement $T$ and the selection of correct base temperature $t_{b h}$. Incorrect base temperature $t_{b h}$ may lead to quite misleading results. Moreover the degree-day method assumes a linear relationship between the temperature above or below the base temperature $t_{b h}$ and space heat demand is proportional to the heating degree days 42,45 . 
(a)

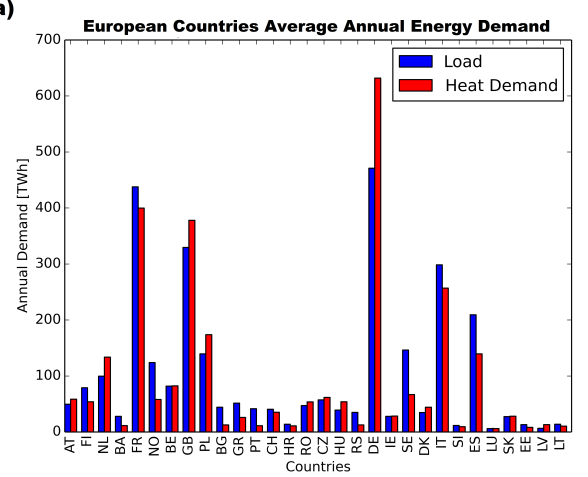

(b)

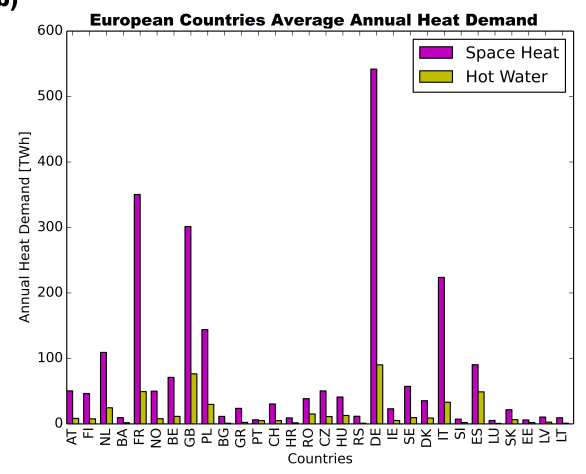

Figure 3: Country specific average annual energy demand in Europe. Fig (a) show annual electrical-load $L_{n}$ (blue) and annual heat demand (red), taken from [26, 32, 49. Fig (b) show share of space heat demand $Q_{s h}$ (magenta) and share of hot water demand $Q_{d h w}$ (yellow) in the annual heat demand $H_{n}$, taken from [50]

\subsubsection{Regression analysis}

As discussed above, the importance of correct base temperature $t_{b h}$ selection. There is no fixed standard value in the literature. The base temperature $t_{b h}$ varies between 15 to $20^{\circ} \mathrm{C}$ by country and region. The base temperature $t_{b h}$ is taken as $17^{\circ} \mathrm{C}$ for the United Kingdom in 42 . Whereas, it is taken as $15^{\circ} \mathrm{C}$ and $18.5^{\circ} \mathrm{C}$ for the Greece in [43, 46]. It is necessary to have a constant base temperature value for the comparison of heat demand between different geographical regions. Therefore, we have calculated an optimum value of base temperature $t_{b h}$ by regression analysis on actual heat demand data (year 2011) for the city of Aarhus, Denmark. This is the method used by Burzynski et al. in [42].

$$
Y_{i}=j x_{i}+\beta_{i}
$$

In the above expression, $Y_{i}$ is the space-heat demand, $j$ is the gradient, $x$ is the degree days and $\beta$ is the error or intercept. The value of base temperature $t_{b h}$ which gives the square of Pearson product moment correlation $(R 2)$ closest to 1 is chosen as an optimum. The correlation is calculated between the space heat demand and degree days. Results from the fig 4 and table 1 show $15^{\circ} \mathrm{C}$ as an optimum base temperature $t_{b h}$. 


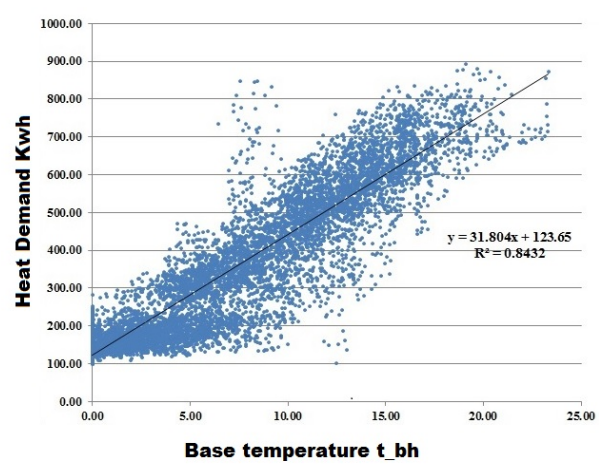

Figure 4: Regression analysis on heat demand (year 2011) for the city of Aarhus (Denmark).

\begin{tabular}{|c|c|c|c|c|c|c|c|c|c|c|c|}
\hline$t_{b h}$ & 15.0 & 15.5 & 16.0 & 16.5 & 17.0 & 17.5 & 18.0 & 18.5 & 19.0 & 19.5 & 20.0 \\
\hline Gradient & 31.8 & 31.1 & 30.5 & 29.9 & 29.5 & 29.1 & 28.7 & 28.4 & 28.1 & 27.9 & 27.6 \\
\hline Intercept & 123.6 & 115.5 & 107.0 & 98.2 & 89.0 & 79.4 & 69.4 & 59.1 & 48.6 & 37.9 & 27.0 \\
\hline R2 & 0.845 & 0.84 & 0.834 & 0.83 & 0.828 & 0.822 & 0.82 & 0.819 & 0.816 & 0.813 & 0.80 \\
\hline
\end{tabular}

Table 1: Results for calculating the optimum base temperature $t_{b h}$ from regression analysis.

\subsubsection{Water heat demand}

Hot water demand $Q_{d h w}$ is calculated from the average annual hot water demand $Q_{d h w_{\text {annual }}}$, taken from [50]. It is assumed that the hot water demand remains constant throughout the year and is proportional to the population density $p$.

$$
Q_{d h w}(t)=\frac{Q_{d h w_{\text {annual }}}}{8760}
$$

\subsection{Heat coupling models}

The feasibility and operational behavior of the following two heat coupling models will be analyzed with different combinations of wind and solar mix $\left(\alpha_{n}\right)$ and renewable energy generation $\left(\gamma_{n}\right)$. These two heat coupling models, heat-pump coupling and electric-resistance coupling were first discussed for the US network (PJM Interconnection) by Pensini et al. in [14]. Besides the method for heat conversion the major difference is the location of heat-storage. Heat-pump coupling has a large scale heat-pump connected with centralize heat-storage, whereas electric-resistance coupling is an on-site model which is installed the consumer's end. However both couplings use an on-site gas-boilers as backup.

Considerable system losses have been taken to get realistic results and assumed that the losses are basically thermal heat losses. The district heating distribution network (DHDN) and heat-storage, thermal energy storage (TES) and high temperature storage(HTS) have an efficiency of 90\%, electric-resistance (R) and gas-boiler (N) have an efficiency of $100 \%$ and heat-pump (HP) has a coefficient of performance (COP) of 3 .

These are the same efficiencies used by Pensini et al. in [14] and results can be compared. 
Technically, there is no difference between the two heat-storage (TES) and (HTS), except the limit on the capacity available for the energy content storage. Thermal energy storage (TES) is a large water energy storage tank located at the district heating company. Conversely, high temperature storage (HTS) is a small ceramic storage $\left(3-6 \mathrm{~m}^{2}\right)$ which can store the hot water for few days [14. Both (TES, HTS) will be called as heat-storage to overcome the confusion.

\subsubsection{Heat-pump coupling}

Heat-pump coupling uses heat-pump to convert excess generation into heat. Heat from the heat-pump (HP) enters the district heating distribution network (DHDN) and is then delivered to consumers. An on-site gas-boiler $(\mathrm{N})$ is also present as a backup heat. In case, if less amount of heat is required by consumers then a centralize heat-storage (TES) is available for the storage of this excess heat. The detailed working principal of this coupling is graphically shown in figure 5 .

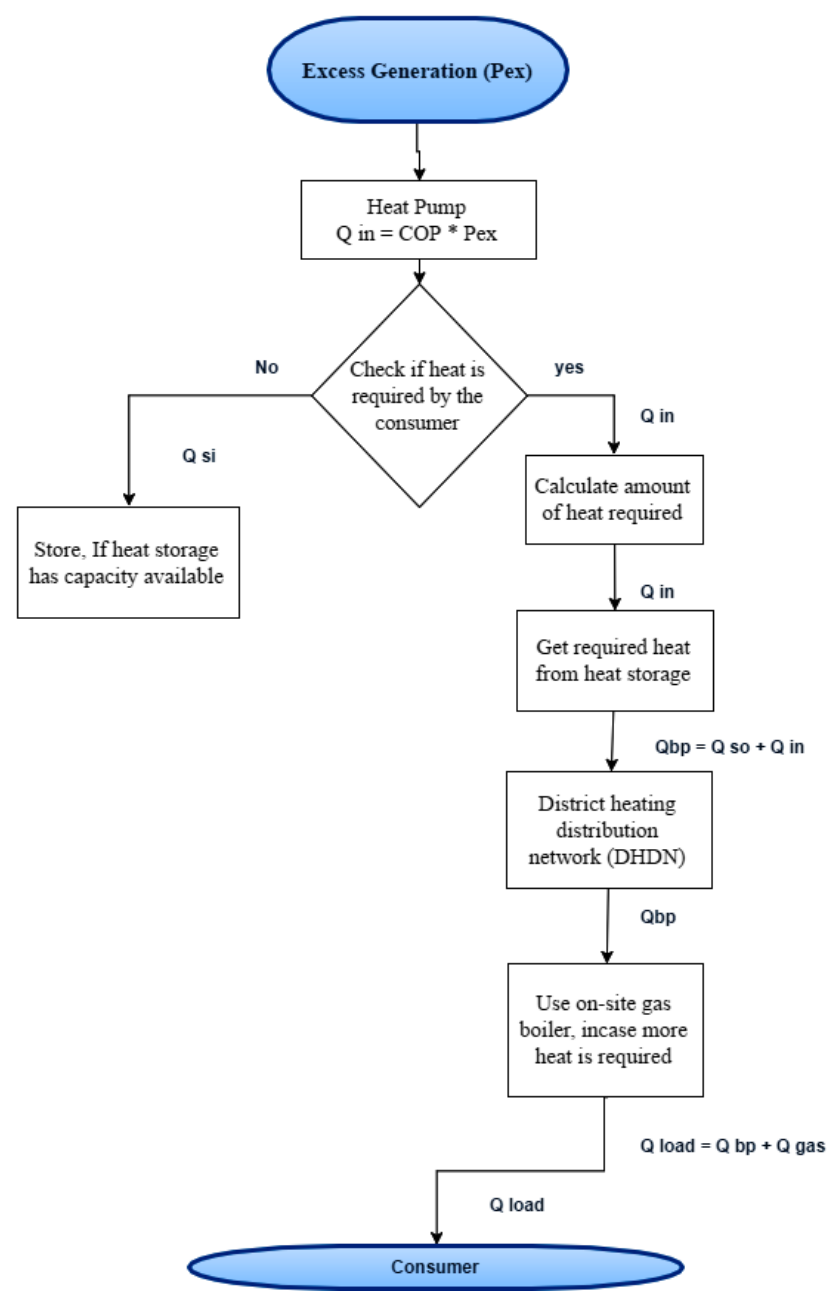

Figure 5: Functional flow block diagram of heat-pump coupling 


\subsubsection{Electric-resistance coupling}

This coupling is simpler than the previous. It uses electrical resistance $(\mathrm{R})$ to convert excess generation into heat which is delivered directly to consumers and an on-site gas-boiler $(\mathrm{N})$ is present as a backup. In case, if there is excess heat then an on-site heat-storage (HTS) is available at consumers end. The detailed working principal of this coupling is graphically shown in figure 6 .

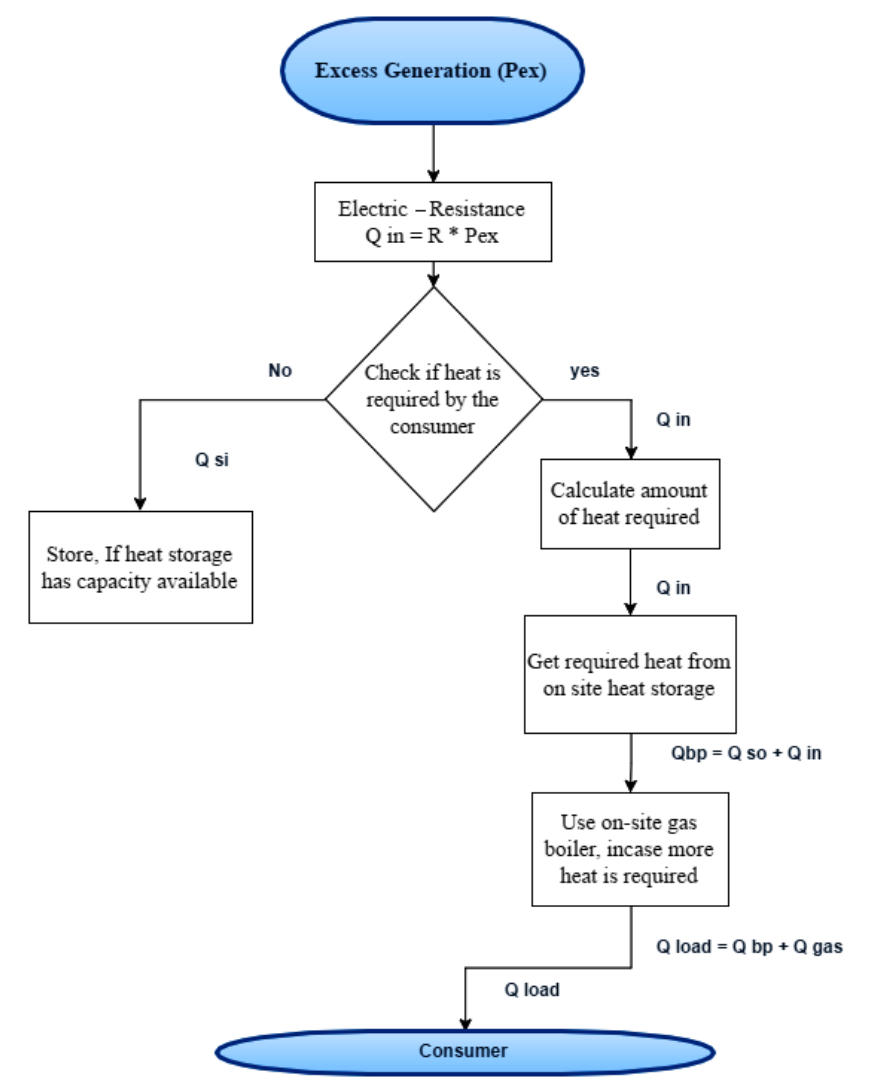

Figure 6: Functional flow block diagram of electric-resistance coupling

\section{Analysis and discussion}

This section present results from this study and compares the outcome from heat coupling models for three different networks i.e pan-European, country and regional network. First, the scope of simulations for the minimum excess generation and backup energy for each electrical grid is discussed. Then the minimum heat-storage energy and gas-boiler energy for both heat couplings is analyzed. Subsequently, the balancing energy with combining both electrical grid and heating sector is evaluated. Later the design parameters for the heat-storage capacity and gas-boiler capacity are calculated. Finally, an optimum energy mix between the heat-storage energy and gas-boiler energy is found.

Electrical-load, generation and heat demand time-series are first calculated at a regional scale of 40x40 $\mathrm{km}^{2}$ from the section 2.2 and 2.4 and then aggregated for a country and pan-European network. Electrical 
grid is assumed to be unconstrained and without losses. In simulations, Denmark is chosen for a country network and the city of Aarhus is selected for a regional network analysis. The actual electrical-load (2009) and heat demand (2011) time-series for the city of Aarhus, Denmark were taken from the Aarhus municipality.

The behavior of each network with combinations of varying wind and solar mix $(\alpha)$ and renewable energy generation $(\gamma)$ is analyzed, and following questions are answered for different scenarios: energy required after the integration of the heating sector, the required heat-storage capacity and gas-boiler capacity required with sharing mismatches, the behavior of a connected pan-European network and decentralized regional networks with heat coupling models.

\subsection{Minimizing excess generation and backup energy}

Excess generation $P_{e x}$ and the possible reduction in backup energy $G_{n}^{B}$ between networks is calculated by comparing the mismatch $\Delta_{n}$ for a regional electrical grid,

$$
P_{e x_{\text {total }}}^{\text {Regional }}=\sum_{t}^{8760} \sum_{n}^{\infty}\left[\Delta_{n}(t)\right]_{+}, G_{n_{\text {total }}}^{B_{\text {Regional }}^{\text {Rel }}}=\sum_{t}^{8760} \sum_{n}^{\infty}\left[\Delta_{n}(t)\right]_{-}
$$

with the pan-European electrical grid.

$$
P_{\text {extotal }}^{\text {Pan-European }}=\sum_{t}^{8760}\left[\sum_{n}^{30} \Delta_{n}(t)\right]_{+}, G_{n_{\text {total }}}^{B^{\text {Pan-European }}}=\sum_{t}^{8760}\left[\sum_{n}^{30} \Delta_{n}(t)\right]_{-}
$$

In regional electrical grid eq. (19), excess generation and backup energy is calculated from the sum of positive and negative mismatch $\Delta_{n}$ in a $40 \times 40 \mathrm{~km}^{2}$ region. However, for the country and pan-European electrical grid eq.20 the mismatches for all $40 \times 40 \mathrm{~km}^{2}$ regions are first added together and then the positive and negative mismatch $\Delta_{n}$ is calculated. Thus, one region's positive mismatch is canceled by others negative mismatch.

In total six simulations are performed and the excess generation and backup energy is analyzed by varying wind and solar mix $(\alpha)$ from 0-1 and renewable energy generation $(\gamma)$ from 0-2. The share of wind generation is maximum at $\alpha=1$. When $\gamma \leq 1$, the renewable energy generation is below or equal to the average electrical-load demand, but when $\gamma>1$ the renewable energy generation is more generated than the required electrical-load demand. This excess generation and backup energy calculation at $\gamma>1$ extends the earlier finding in $9,24,26,28$ and adds regional electrical grid into the analysis.

It is observed that all electrical grids behave similarly but the pan-European electrical grid has least requirement for the backup energy. The backup energy in all networks reduces with the increase in wind generation and renewable energy generation, but it reduces drastically at the renewable energy generation $\gamma \geq 1.5$. These results are similar to the ones discussed by Rolando et. al [26] and Becker et. al [28, where the connected electrical grid leads to the reduction of backup energy by around two fifth for a pan-European network and around one fourth for the contiguous US electrical grid. 
The excess generation shows trend opposite to the backup energy. In this study it is found that this reduction in backup energy $G_{n}^{B}$ comes at an expense of reduction in the excess generation $P_{e x}$. Excess generation for the pan-European electrical grid is reduced by almost $40 \%$ than available in the regional electrical grid. This limits the feasibility of the heat coupling for the pan-European electrical grid. Furthermore, there is quite an increase in the excess generation obsereved after the renewable energy generation $\gamma>1$. This is similar to the high penetration of renewable energy in the US network (PJM Interconnection) discussed by Budischak et al. [13] and Pensini et al. [14]. These results for the backup energy and excess generation are shown in fig 7 .

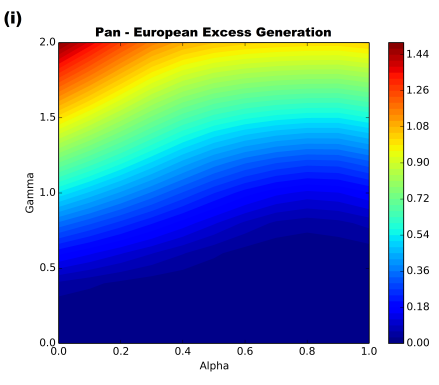

(iv)

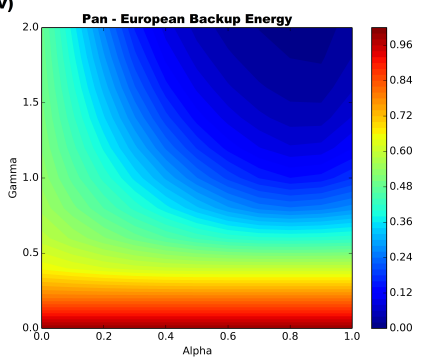

(ii)

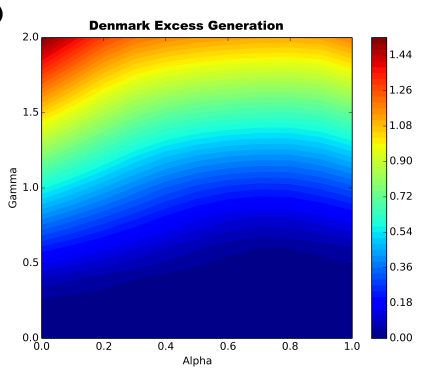

(v)

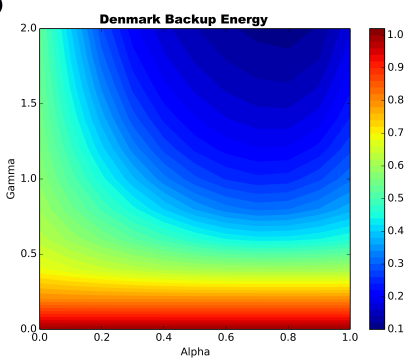

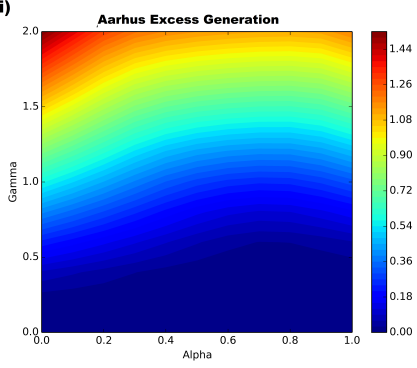

(vi)

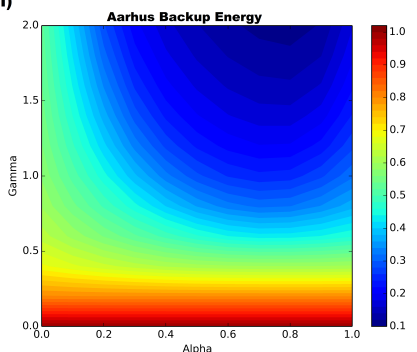

Figure 7: Excess generation $\left\langle P_{e x}\right\rangle$ and backup energy $\left\langle G_{n}^{B}\right\rangle$, as a function of wind/solar mix $(\alpha)$ and renewable energy generation $(\gamma)$ for the pan-European electrical grid (first column), Denmark electrical grid (central column) and Aarhus electrical grid (last column). Figs (i),(ii),(iii) represents the excess generation $\left\langle P_{e x}\right\rangle$ and figs (iv),(v),(vi) represents the backup energy $\left\langle G_{n}^{B}\right\rangle$. Here, excess generation $\left\langle P_{e x}\right\rangle$ and backup energy $\left\langle G_{n}^{B}\right\rangle$ are the mean of annual time-series (8760) and both are normalized to each networks average electrical-load. (For interpretation of the references to color in this figure legend, the reader is adviced to refer to the web version of this article).

\subsubsection{Optimum wind and solar mix}

Backup energy $G_{n}^{B}$ in each network has to be fulfilled from other conventional and instantaneous emergency energy sources, as no electrical storage is assumed to be present. An optimum wind and solar mix for the minimum backup energy is calculated and results are compared.

$$
G_{n}^{B^{\mathrm{opt}}}=\min _{\alpha_{n}^{W}} \sum_{t}\left[\Delta_{n}(t)\right]_{-}
$$

Backup energy varies with increase in the share of wind generation and is found to be minimum at wind and solar mix of $80 / 20$, than the wind only generation. Backup energy for the pan-European electrical grid is 
found to be minimum among all networks and requires upto $26 \%$ of less energy than the wind only generation. Whereas, backup energy for the country and regional electrical grid is identical. These optimal wind and solar mix results for the pan-European electrical grid are same as discussed by Rasmussen et. al [9] and can be observed in fig 8

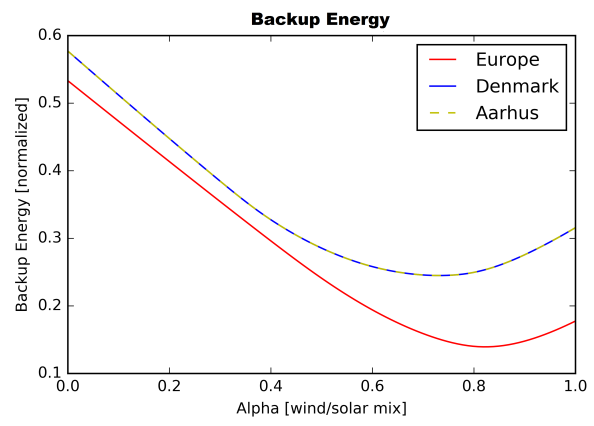

Figure 8: Backup energy $\left\langle G_{n}^{B}\right\rangle$ as a function of wind/solar mix $(\alpha)$ and renewable energy generation $(\gamma=1)$ for each network.

\subsection{Minimizing heat-storage and gas-boiler energy}

between the heat demand $H_{n}$ and excess generation $P_{e x_{n}}$. The possible reduction in the heat-storage energy and gas-boiler energy is calculated by comparing the heat mismatch $\tilde{\Delta}_{H_{n}}$ between the regional network,

$$
E_{\text {total }}^{\text {Regional }}=\sum_{t}^{8760} \sum_{n}^{\infty}\left[\tilde{\Delta}_{H_{n}}(t)\right]_{-}, N_{\text {total }}^{\text {Regional }}=\sum_{t}^{8760} \sum_{n}^{\infty}\left[\tilde{\Delta}_{H_{n}}(t)\right]_{+}
$$

with the pan-European network.

$$
E_{\text {total }}^{\text {Pan-European }}=\sum_{t}^{8760}\left[\sum_{n}^{30} \tilde{\Delta}_{H_{n}}(t)\right]_{-}, N_{\text {total }}^{\text {Pan-European }}=\sum_{t}^{8760}\left[\sum_{n}^{30} \tilde{\Delta}_{H_{n}}(t)\right]_{+}
$$

As in 3.1, the heat-storage energy and gas-boiler energy for a regional network eq.22 is calculated from the negative and positive heat mismatch $\tilde{\Delta}_{H_{n}}$ in a $40 \mathrm{x} 40 \mathrm{~km}^{2}$ region. However, for the country and panEuropean network eq. 23 the heat mismatches for all $40 \times 40 \mathrm{~km}^{2}$ regions are first added together and then the positive and negative heat mismatch $\tilde{\Delta}_{H_{n}}$ is calculated.

In total twelve simulations are performed and the required heat-storage energy and gas-boiler energy is compared for each network. It is found, heat-storage energy is lowest for the regional network and gasboiler energy is lowest for the country network. The pan-European network and regional network behave quite similarly with increase in the renewable energy generation $(\gamma)$, but major difference is observed in the heat-storage energy.

It is usually undesirable to increase the renewable energy generation greater than the electrical-load demand, but it is found that the gas-boiler energy becomes minimal at the renewable energy generation $\gamma \geq$ 1.5. Budischak et al. 13] and Pensini et al. 14 have also concluded that energy costs for the US network 
While analyzing two heat coupling models it is observed, heat-pump coupling provides almost 4 times more heat-storage energy and requires upto $38 \%$ less gas-boiler energy than the electric-resistance coupling. These observations, especially increase in the heat-storage energy have been discussed for the US network (PJM Interconnection) by Pensini et. al [14. The behavior of both heat couplings with the variation in wind and solar mix $(\alpha)$ from 0-1 and renewable energy generation $(\gamma)$ from 0-2 is shown in fig 9, and results are summarized in table (2).

\subsubsection{Optimum wind and solar mix}

As mentioned above, the heat-storage energy and gas-boiler energy depends on the wind and solar mix. An optimum wind and solar mix is substantial for calculating the minimum energy needs in each network.

$$
E_{n}^{\mathrm{opt}}=\min _{\alpha_{n}^{W}} \sum_{t}\left[\tilde{\Delta}_{H_{n}}(t)\right]_{-}, \quad N_{n}^{\mathrm{opt}}=\min _{\alpha_{n}^{W}} \sum_{t}\left[\tilde{\Delta}_{H_{n}}(t)\right]_{+}
$$

The higher values of the heat-storage energy and gas-boiler energy will explain the greater amount of heat-storage capacity and gas-boiler capacity is required by the network. Heat-storage energy is found to be minimum for the regional network and gas-boiler energy is minimum for the country network. However, interestingly the optimum wind and solar mix for all networks is at $80 / 20$. Heat storage energy is minimum at the wind solar mix of $80 / 20$, but the gas-boiler energy is minimum for wind only generation than with the wind/solar mix. These results suggests that this strong correlation between the wind generation and heat demand in Europe can be used for the reduction of gas-boiler energy. This gives Europe with greater potential of wind generation utilization for the heating sector than US network (PJM Interconnection). These results are shown as shown in fig 10 .

With heat-pump coupling, the heat-storage energy is reduced by almost $46 \%$ and the gas-boiler energy is increased by almost $12 \%$ at wind and solar mix of $80 / 20$, than a wind only generation. However, with electric-resistance coupling the heat-storage energy is reduced by almost $57 \%$ and the gas-boiler energy is increased by almost $7 \%$ at wind and solar mix of $80 / 20$, than a wind only generation.

It is observed that the heat-pump coupling provides 4 times more heat-storage energy than the electricresistance coupling. This can be explained due to the coefficient of performance (COP) of a heat-pump. These observations give another perspective to earlier findings in [22, 26, 28, where an interconnected electrical grid leads to lowering the backup energy. These results for both heat couplings are summarized in table (2).

\subsection{Minimizing balancing energy}

Balancing energy $B_{n}$ is the total energy required by a network when both electrical grid and heating sector are combined together. It is the sum of backup energy $G_{n}^{B}$ and gas-boiler energy $N_{n}$.

$$
B_{n}=G_{n}^{B}+N_{n}
$$

As calculated earlier, backup energy $G_{n}^{B}$ is minimum for the pan-European electrical grid. Heat-storage energy $E_{n}$ and gas-boiler energy $N_{n}$ are minimum for the regional network and country network respectively. 
(i)

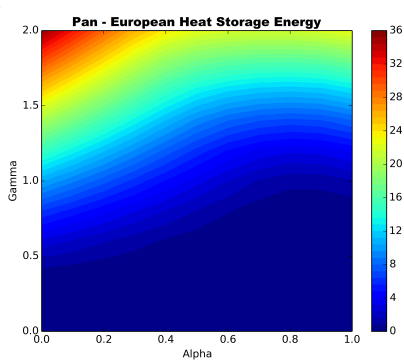

(iv)
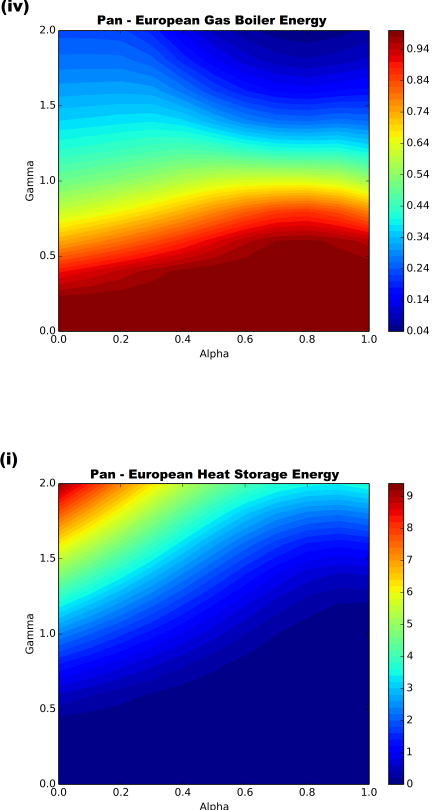

(iv)

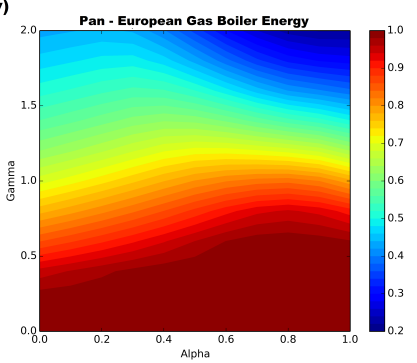

(ii)

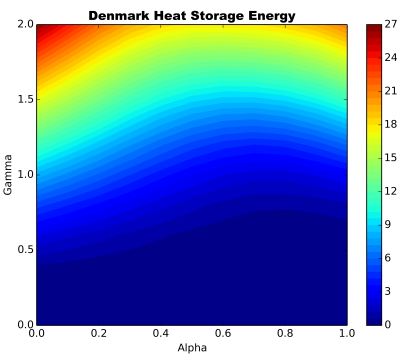

(v)

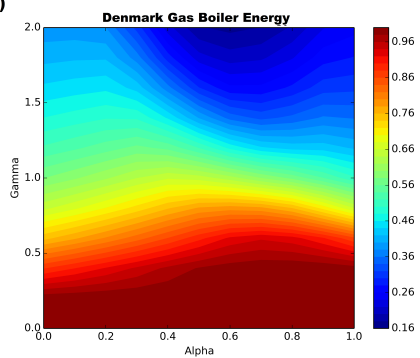

(a) Heat-pump coupling

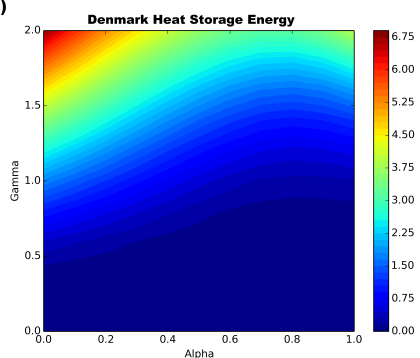

(v)

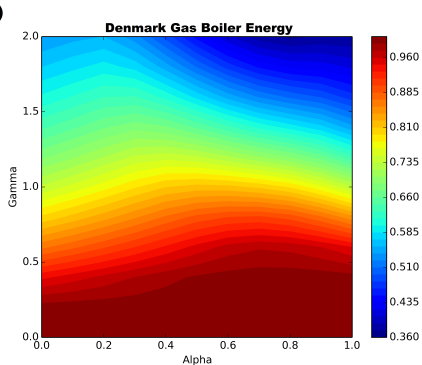

(iii)
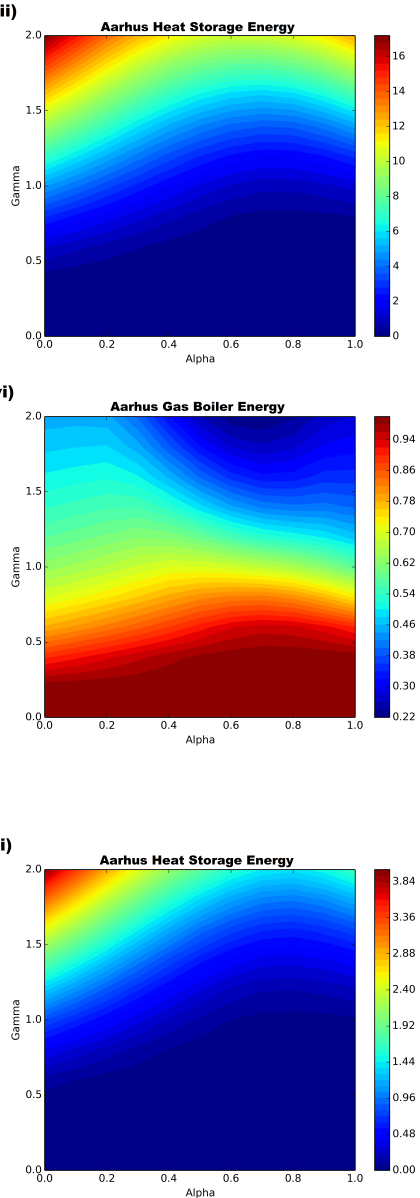

(vi)

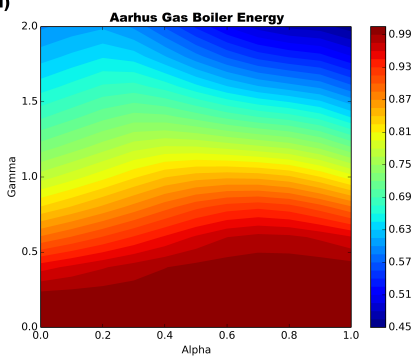

(b) Electric-resistance coupling

Figure 9: Heat-storage energy $\left\langle E_{n}\right\rangle$ and gas-boiler energy $\left\langle N_{n}\right\rangle$ as a function of wind/solar mix $(\alpha)$ and renewable energy generation $(\gamma)$ for the pan-European network (first column), Denmark network (central column) and regional network (last column). Figs (a)(i),(ii),(iii) represents the heat-storage energy $\left\langle E_{n}\right\rangle$ and figs (a)(iv),(v),(vi) represents the gas-boiler energy $\left\langle N_{n}\right\rangle$ for networks with heat-pump coupling. Figs (b)(i),(ii),(iii) represents the heat-storage energy $\left\langle E_{n}\right\rangle$ and figs(b)(iv),(v),(vi) represents the gas-boiler energy $\left\langle N_{n}\right\rangle$ for networks with the electric-resistance coupling. Here, heat-storage energy $\left\langle E_{n}\right\rangle$ and gas-boiler energy $\left\langle N_{n}\right\rangle$ are the mean of annual time-series (8760) and both are normalized to each networks average electricalload. (For interpretation of the references to color in this figure legend, the reader is adviced to refer to the web version of this article). 


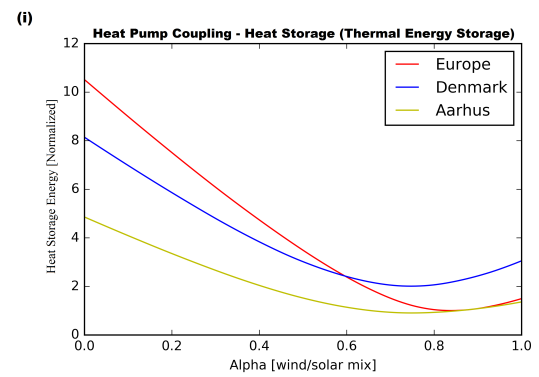

(iii)

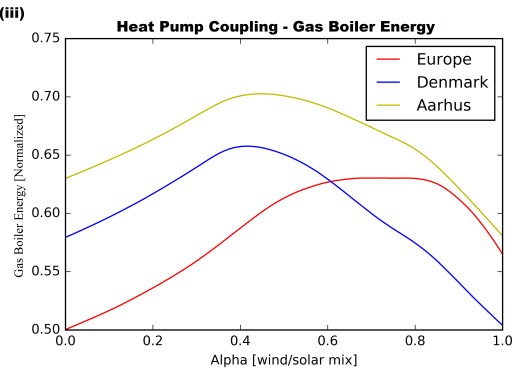

(ii)

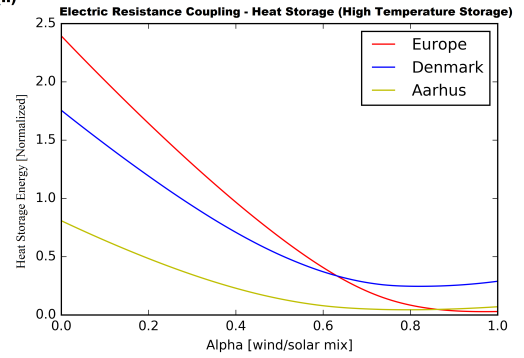

(iv)

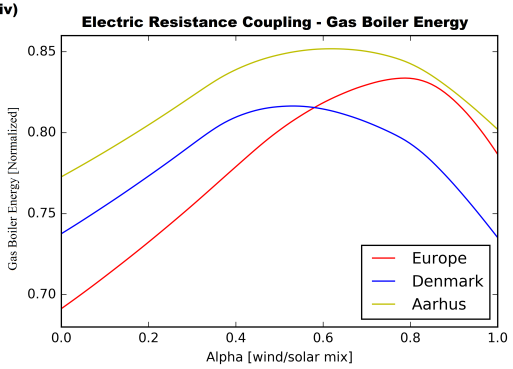

Figure 10: Heat-storage energy $\left\langle E_{n}\right\rangle$ and gas-boiler energy $\left\langle N_{n}\right\rangle$ as a function of wind/solar mix $(\alpha)$ and renewable energy generation $(\gamma=1)$ for each network. Figs (a),(c) show networks with heat-pump coupling and figs (b), (d) show networks with electric-resistance coupling.

However, the pan-European network has the least amount of balancing energy $B_{n}$ and is found to be minimum at a wind and solar mix of $80 / 20$. This reduction in balancing energy for the pan-European network is only because of the backup energy requirements in a lossless electrical grid, otherwise the standalone heat coupling for the regional network has the lowest energy demand.

Heat-pump coupling requires upto $26 \%$ less balancing energy than the electric-resistance coupling. Balancing energy for each network with the varying wind and solar mix can be observed in figure 11. A brief comparison between networks is given in table 2 .
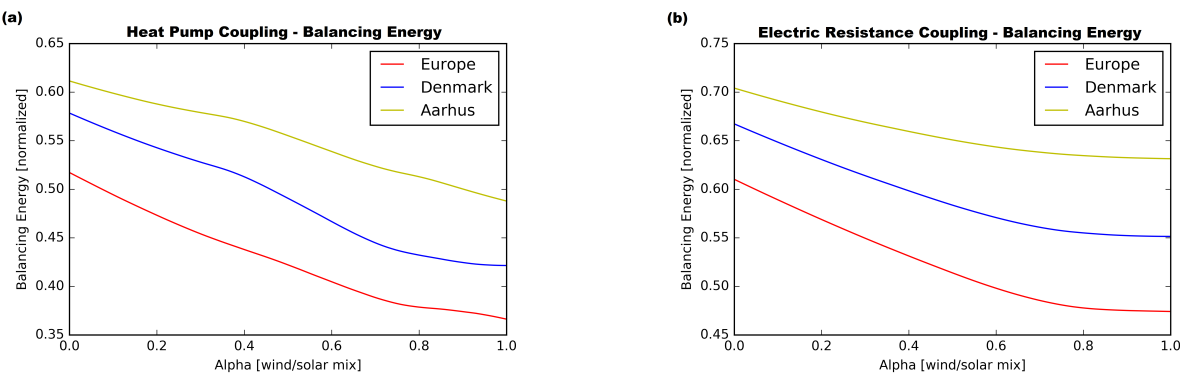

Figure 11: Balancing energy $\left\langle B_{n}\right\rangle$ as a function of wind/solar mix $(\alpha)$ and renewable energy generation $(\gamma=1)$. Fig (a) show networks with heat-pump coupling and fig (b) show networks with electric-resistance coupling. (For interpretation of the references to color in this figure legend, the reader is adviced to refer to the web version of this article). 


\begin{tabular}{|c|c|c|c|c|c|}
\hline \multicolumn{6}{|c|}{ Heat-pump coupling } \\
\hline & $\left\langle G_{n}^{B}\right\rangle$ & $\left\langle P_{e x}\right\rangle$ & $\left\langle N_{n}\right\rangle$ & $\left\langle E_{n}\right\rangle$ & $\left\langle B_{n}\right\rangle$ \\
\hline Pan-European & 0.15 & 0.15 & 0.63 & 1.04 & 0.38 \\
\hline Individual country & 0.24 & 0.24 & 0.57 & 2.06 & 0.43 \\
\hline Regional & 0.24 & 0.24 & 0.65 & 0.93 & 0.51 \\
\hline \multicolumn{6}{|c|}{ Electric-resistance coupling } \\
\hline & $\left\langle G_{n}^{B}\right\rangle$ & $\left\langle P_{e x}\right\rangle$ & $\left\langle N_{n}\right\rangle$ & $\left\langle E_{n}\right\rangle$ & $\left\langle B_{n}\right\rangle$ \\
\hline Pan-European & 0.15 & 0.15 & 0.83 & 0.08 & 0.48 \\
\hline Individual country & 0.24 & 0.24 & 0.79 & 0.25 & 0.55 \\
\hline Regional & 0.24 & 0.24 & 0.84 & 0.04 & 0.63 \\
\hline
\end{tabular}

Table 2: Comparison between the backup energy $\left\langle G_{n}^{B}\right\rangle$, excess generation $\left\langle P_{e x}\right\rangle$, gas-boiler energy $\left\langle N_{n}\right\rangle$, heat-storage energy $\left\langle E_{n}\right\rangle$ and balancing energy $\left\langle B_{n}\right\rangle$ for each network with heat coupling. These calculations are at the wind/solar mix $(\alpha=0.8)$ and renewable energy generation $(\gamma=1)$. Here, $\left\langle G_{n}^{B}\right\rangle$ and $\left\langle P_{e x}\right\rangle$ are normalized to average electrical-load demand $\left\langle L_{n}\right\rangle$ for each electrical grid and $\left\langle N_{n}\right\rangle$ and $\left\langle E_{n}\right\rangle$ are both normalized to average heat demand $\left\langle H_{n}\right\rangle$ for each network. However, $B_{n}$ is normalized to the average of the combined electrical-load demand and heat demand $\left\langle L_{n}+H_{n}\right\rangle$ for each network.

\subsection{Heat-storage and gas-boiler capacity}

In this study, the most important analysis to facilite investors and policy makers is the heat-storage capacity and gas-boiler capacity required by each network. It gives a measure of annual energy usage with each heat coupling. Heat-storage capacity $\mathcal{K}^{E_{n}}$ is calculated from 'quantile method'. This method is used for calcuating transmission and backup capacities in [11, 25, 26]. Heat-storage capacity that can cover $99 \%$ events is estimated by taking $99 \%$ quantile of the heat-storage usage time-series.

$$
\begin{gathered}
q_{n}=\int_{0}^{E_{n}} p_{n}\left(E_{n}\right) d E_{n} \\
\mathcal{K}^{E_{n}}=E_{n}^{99 \%}
\end{gathered}
$$

Whereas, gas-boiler capacity $\mathcal{K}^{N_{n}}$ is calculated from the average of gas-boiler usage time-series, as calculation from the quantile method lead to its overestimation.

$$
\mathcal{K}^{N_{n}}=\left\langle N_{n}\right\rangle_{t}
$$

It is calculated that the heat-storage capacity $\mathcal{K}^{E_{n}}$ is minimum for the regional network and gas-boiler capacity $\mathcal{K}^{N_{n}}$ is minimum for the country network. With heat-pump coupling, the heat-storage capacity $\mathcal{K}^{E_{n}}$ is reduced by $3 \%$ and the gas-boiler capacity $\mathcal{K}^{N_{n}}$ is reduced by $9 \%$ as compared to the pan-European network. However, with electric-resistance coupling the heat-storage capacity $\mathcal{K}^{E_{n}}$ is reduced by $26 \%$ and the gas-boiler capacity $\mathcal{K}^{N_{n}}$ is reduced by $5 \%$ as compared to the pan-European network. These results are shown and compared in figure 12 . 
This gives another perspective to the earlier findings on an interconnected pan-European electrical grid from Becker et.al 25] and Rolando et.al [26. We find that the pan-European with heat coupling network does not lead to reduction in the heat-storage capacity $\mathcal{K}^{E_{n}}$ and gas-boiler capacity $\mathcal{K}^{N_{n}}$.

It can be summarized that there is also a strong correlation between the heat-storage energy and heatstorage capacity requirement. Heat-pump coupling requires almost 4 times more heat-storage capacity and upto $38 \%$ less gas-boiler capacity than the electric-resistance coupling. The electric-resistance coupling requires less heat-storage capacity but at the expense of higher gas-boiler capacity.
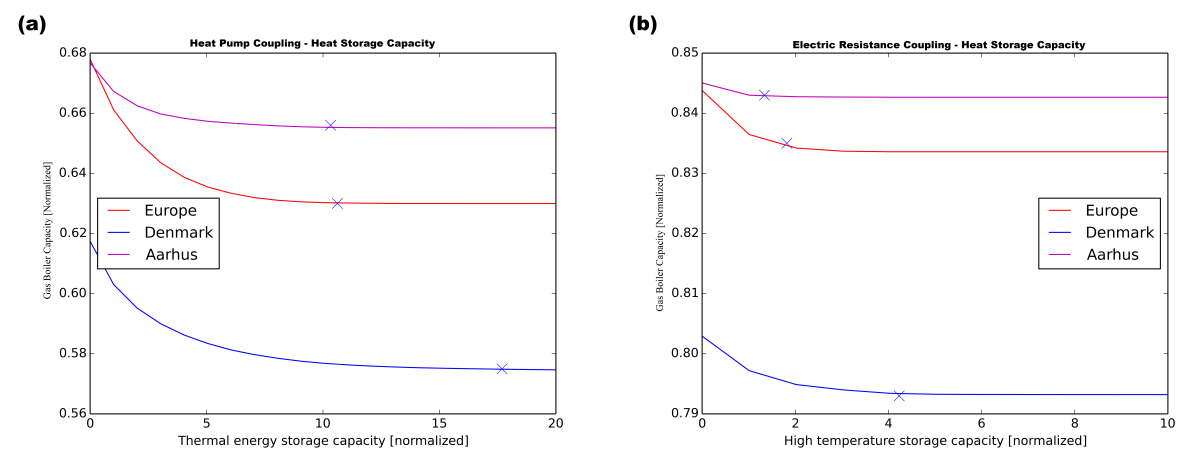

Figure 12: Heat-storage capacity $\mathcal{K}^{E_{n}}$ and gas-boiler capacity $\mathcal{K}^{N_{n}}$ as a function of at wind and solar mix $(\alpha=0.8)$ and renewable energy generation $(\gamma=1)$. Fig (a) show result for networks with heat-pump coupling and fig (b) show result for networks with electric-resistance coupling. Here, blue cross marker represents $99 \%$ quantile.(For interpretation of the references to color in this figure legend, the reader is adviced to refer to the web version of this article).

\subsection{Optimum heat-storage and gas-boiler energy mix}

Energy mix between the heat-storage and gas-boiler gives the operational parameters for each network with heat coupling. The optimal energy mix which leads to the minimum residual heat mismatch is measured by assuming that both heat-storage and gas-boiler have the same operational cost. From the residual heat mismatch $v_{n}$ eq (11),

$$
\begin{gathered}
v_{n}(t)=\tilde{\Delta}_{H_{n}}(t)+E_{n}(t)-N_{n}(t) \\
\text { Heat-deficit }=\left[\tilde{\Delta}_{H_{n}}(t)+\left[\sigma_{n} \cdot E_{n}(t)-\left(1-\sigma_{n}\right) N_{n}(t)\right]\right]_{+}
\end{gathered}
$$

Heat-deficit is calculated from the positive value of residual heat mismatch $v_{n}$. Here, $\sigma$ defines the share between the heat-storage $E_{n}$ and gas-boiler $N_{n}$. The relative share of energy from heat-storage is $\sigma_{n} . E_{n}$ and the corresponding share of gas-boiler energy is $\left(1-\sigma_{n}\right) N_{n}$.

The optimum energy mix is measured as $10 / 90$ for the heat-pump coupling and 2/98 for the electricresistance coupling. This low share of heat-storage energy shows that currently less amount of excess generation is available for the heat-storage. But, infuture if the renewable energy generation $(\gamma)$ is increased by 
$50 \%$ then the optimum energy mix increases to 30/70 for the heat-pump coupling and 10/90 for the electricresistance coupling. Pensini et. al [14] has also suggested same for the US network (PJM Interconnection) and concluded that the consumption of gas-boiler is reduced to as-little as $3 \%$ with the current amount of excess generation. These energy mix results for European networks are shown in figure 13 .

(i)

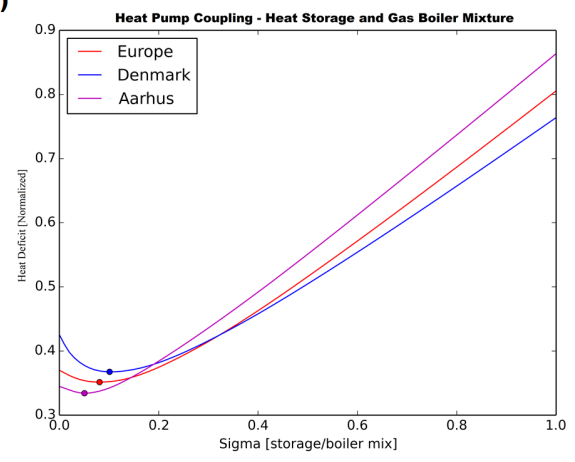

(a) Energy mix at generation $\gamma=1$

(iii)

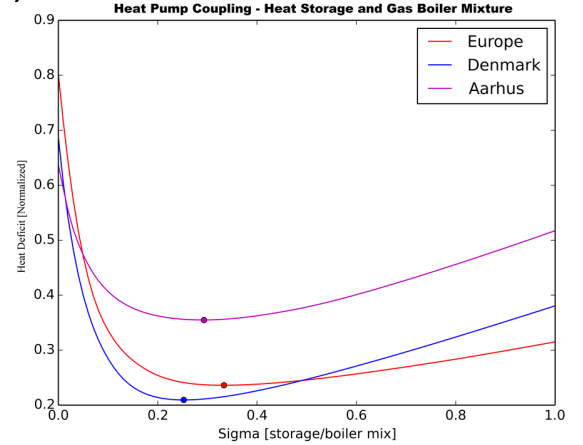

(ii)

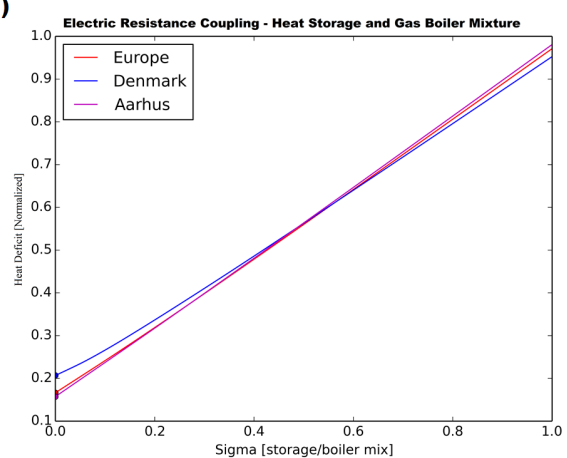

(iv)

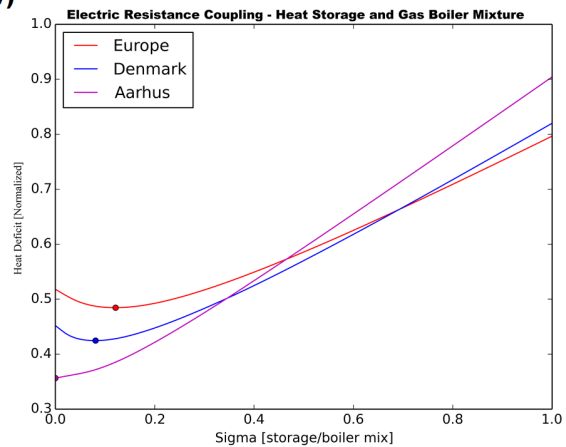

(b) Energy mix at generation $\gamma=1.5$

Figure 13: Heat-deficit as a function of heat-storage/gas-boiler mix $(\sigma)$ for each network. Figs (a)(i),(ii) show energy mix for networks with heat-pump and electric-resistance coupling at wind/solar mix $(\alpha=0.8)$ and renewable energy generation $(\gamma=1)$. Figs (b)(iii),(iv) show energy mix for networks with heat-pump and electric-resistance coupling at wind/solar mix $(\alpha=0.8)$ and renewable energy generation $(\gamma=1.5)$.(For interpretation of the references to color in this figure legend, the reader is adviced to refer to the web version of this article).

\section{Conclusion}

A unique geographical heat demand calculation model for any place in Europe has been presented and benefits with the integration of heating sector into future highly renewable energy electrical grid are quantified. The possibility of excess generation utilization with two variants of heat coupling, heat-pump coupling and electric-resistance coupling, has been discussed and analysis is performed on regional, country and pan- 
European network. The calculation for the minimum need for backup energy, gas-boiler energy and balancing energy with varying wind and solar mix show that the optimal wind and solar mix remains constant at 80/20.

\section{Acknowledgments}

AA is really grateful to Martin Greiner, Gorm B. Andresen and Marcus Therkildsen from Aarhus University for providing data, continuous guidance and helpful constructive discussions during this research. Moreover Magnus Dahl for providing heat demand data for the Aarhus municipality. Furthermore, gratefully

Furthermore, the heat-storage-capacity and gas-boiler capacity requirement depends on the wind and solar mix. Coupling with the regional network reduces the heat-storage capacity by upto $26 \%$ and coupling with an individual country network reduces the gas-boiler capacity by upto $9 \%$. However, coupling with the pan-European network results into reduction of balancing energy by $34 \%$.

Furthermore, the influence with the implementation of heat-pump coupling and electric-resistance coupling on each network is investigated. It is concluded that the heat-pump coupling provides more benefit than the electric-resistance coupling and its integration in our system requires less alterations. With heat-pump coupling, heat-storage energy is increased by 4 times and the requirement for gas-boiler energy and balancing energy is reduced by upto $38 \%$ and $26 \%$ as compared to electric-resistance coupling. It is also concluded from the optimum energy mix between heat-storage and gas-boiler that the current excess generation is not enough to fully support the heating sector. But, if the renewable energy generation is increased by $50 \%$ then the required gas-boiler energy becomes minimal and the energy mix is increased from 10/90 to 30/70.

Transition to $\mathrm{CO}_{2}$ free renewable based heating sector seems realistic, but the heat-storage requirement will be critical in the selection of heat coupling technology. If we summarize the above discussion, then a connected pan-European electrical grid with decentralized regional heat-pump coupling seems promising.

It is also envisioned that heat-pump coupling can be instrumental in increasing energy footprints, especially with its flexibility in combining with the latest advanced low temperature district heating and cooling systems [51] and solar and concentrated solar power (CSP) systems [52, 53]. Cost-effective utilization of the full resources can be achieved by demand side management, development of probabilistic models for the correct prediction of an individual building heat demand [34] and coupling with the transportation sector and other future energy infrastructures.

acknowledges the partial financial support from Leonardo office Brandenburg at BTU Cottbus - Senftenberg and Pastor Reinhard Menzel.

\section{References}

[1] McKinsey, KEMA, T. E. F. L. at Imperial College London, O. Economics, ECF, Roadmap 2050: A practical guide to a prosperous, low-carbon europe, Tech. rep., European Climate Foundation (2010). 
[2] D. Connolly, H. Lund, B. Mathiesen, S. Werner, B. Mller, U. Persson, T. Boermans, D. Trier, P. stergaard, S. Nielsen, Heat roadmap europe: Combining district heating with heat savings to decarbonise the $\{$ EU\} energy system, Energy Policy 65 (2014) 475 - 489. doi:http://dx.doi.org/10.1016/j. enpol.2013.10.035

URL http://www.sciencedirect.com/science/article/pii/S0301421513010574

[3] M. A. Delucchi, M. Z. Jacobson, Providing all global energy with wind, water, and solar power, part ii: Reliability, system and transmission costs, and policies, Energy Policy 39 (3) (2011) 1170 - 1190. doi:http://dx.doi.org/10.1016/j.enpol.2010.11.045

URL http://www.sciencedirect.com/science/article/pii/S0301421510008694

[4] M. Z. Jacobson, M. A. Delucchi, Providing all global energy with wind, water, and solar power, part i: Technologies, energy resources, quantities and areas of infrastructure, and materials, Energy Policy 39 (3) (2011) 1154 - 1169. doi:http://dx.doi.org/10.1016/j.enpol.2010.11.040.

URL http://www.sciencedirect.com/science/article/pii/S0301421510008645

[5] H. Lund, B. Mathiesen, Energy system analysis of 100\% renewable energy systemsthe case of denmark in years 2030 and 2050, Energy 34 (5) (2009) 524 - 531, 4th Dubrovnik Conference4th Dubrovnik conference on Sustainable Development of energy, Water \& amp; Environment. doi:http://dx.doi. org/10.1016/j.energy.2008.04.003 URL http://www.sciencedirect.com/science/article/pii/S0360544208000959

[6] D. Connolly, H. Lund, B. Mathiesen, M. Leahy, The first step towards a $100 \%$ renewable energy system for ireland, Appl Energy 88. doi:10.1016/j.apenergy.2010.03.006.

URL http://dx.doi.org/10.1016/j.apenergy.2010.03.006

[7] Z. Glasnovic, J. Margeta, Vision of total renewable electricity scenario, Renewable and Sustainable Energy Reviews 15 (4) (2011) 1873 - 1884. doi:http://dx.doi.org/10.1016/j.rser.2010.12.016. URL http://www.sciencedirect.com/science/article/pii/S136403211000451X

[8] H. Lund, Renewable energy strategies for sustainable development, Energy 32 (6) (2007) 912 - 919, third Dubrovnik Conference on Sustainable Development of Energy, Water and Environment Systems. doi:http://dx.doi.org/10.1016/j.energy.2006.10.017 URL http://www.sciencedirect.com/science/article/pii/S036054420600301X

[9] M. G. Rasmussen, G. B. Andresen, M. Greiner, Storage and balancing synergies in a fully or highly renewable pan-european power system, Energy Policy 51 (2012) 642 - 651, renewable Energy in China. doi:http://dx.doi.org/10.1016/j.enpol.2012.09.009

URL http://www.sciencedirect.com/science/article/pii/S0301421512007677 
[10] S. Weitemeyer, D. Kleinhans, T. Vogt, C. Agert, Integration of renewable energy sources in future power

a systems: The role of storage, Renewable Energy 75 (2015) 14 - 20. doi:http://dx.doi.org/10.1016/ j.renene.2014.09.028. URL http://www.sciencedirect.com/science/article/pii/S096014811400593X

[11] R. A. Rodriguez, S. Becker, M. Greiner, Cost-optimal design of a simplified, highly renewable panㅁ european electricity system, Energy 83 (2015) 658-668. doi:http://dx.doi.org/10.1016/j.energy. 2015.02 .066

URL http://www.sciencedirect.com/science/article/pii/S0360544215002212

${ }_{410}^{4}[12]$ S. Becker, B. A. Frew, G. B. Andresen, M. Z. Jacobson, S. Schramm, M. Greiner, Renewable build-up 口 pathways for the us: Generation costs are not system costs, Energy 81 (2015) 437 - 445. doi:http: //dx.doi.org/10.1016/j.energy.2014.12.056 URL http://www.sciencedirect.com/science/article/pii/S0360544214014285

[13] C. Budischak, D. Sewell, H. Thomson, L. Mach, D. E. Veron, W. Kempton, Cost-minimized combinations of wind power, solar power and electrochemical storage, powering the grid up to $99.9 \%$ of the time,

1. Journal of Power Sources 225 (2013) 60 - 74. doi:http://dx.doi.org/10.1016/j.jpowsour.2012. 09.054

URL http://www.sciencedirect.com/science/article/pii/S0378775312014759

[14] A. Pensini, C. N. Rasmussen, W. Kempton, Economic analysis of using excess renewable electricity to displace heating fuels, Applied Energy 131 (2014) 530 - 543. doi:http://dx.doi.org/10.1016/j. apenergy.2014.04.111.

URL http://www.sciencedirect.com/science/article/pii/S0306261914004772

[15] T. Bomann, R. Elsland, A.-L. Klingler, G. Catenazzi, M. Jakob, Sustainability in energy and buildings:

口 Proceedings of the 7th international conference seb-15 assessing the optimal use of electric heating systems for integrating renewable energy sources, Energy Procedia 83 (2015) 130 - 139. doi:http: //dx.doi.org/10.1016/j.egypro.2015.12.203

URL http://www.sciencedirect.com/science/article/pii/S1876610215028684

[16] B. Bach, J. Werling, T. Ommen, M. Mnster, J. M. Morales, B. Elmegaard, Integration of large-scale a heat pumps in the district heating systems of greater copenhagen, Energy 107 (2016) 321 - 334. doi: http://dx.doi.org/10.1016/j.energy.2016.04.029.

URL http://www.sciencedirect.com/science/article/pii/S0360544216304352

[17] T. Ommen, W. B. Markussen, B. Elmegaard, Lowering district heating temperatures impact to system performance in current and future danish energy scenarios, Energy 94 (2016) 273 - 291. doi:http: //dx.doi.org/10.1016/j.energy.2015.10.063 
[18] H. Lund, Implementation of energy-conservation policies: the case of electric heating conversion in denmark, Applied Energy 64 (14) (1999) 117 - 127. doi:http://dx.doi.org/10.1016/S0306-2619(99) 00066-5.

URL http://www.sciencedirect.com/science/article/pii/S0306261999000665

[26] R. A. Rodrguez, S. Becker, G. B. Andresen, D. Heide, M. Greiner, Transmission needs across a fully 465

[19] J. Z. Thellufsen, H. Lund, Energy saving synergies in national energy systems, Energy Conversion and Management 103 (2015) 259 - 265. doi:http://dx.doi.org/10.1016/j.enconman.2015.06.052. URL http://www.sciencedirect.com/science/article/pii/S0196890415005932

[20] K. Bauermann, German energiewende and the heating market impact and limits of policy, Energy Policy 94 (2016) 235 - 246. doi:http://dx.doi.org/10.1016/j.enpol.2016.03.041. URL http://www.sciencedirect.com/science/article/pii/S0301421516301410

[21] U. Persson, B. Mller, S. Werner, Heat roadmap europe: Identifying strategic heat synergy regions, Energy Policy 74 (2014) 663 - 681. doi:http://dx.doi.org/10.1016/j.enpol.2014.07.015 URL http://www.sciencedirect.com/science/article/pii/S0301421514004194

[22] D. Heide, L. von Bremen, M. Greiner, C. Hoffmann, M. Speckmann, S. Bofinger, Seasonal optimal mix of wind and solar power in a future, highly renewable europe, Renewable Energy 35 (11) (2010) 2483 2489. doi:http://dx.doi.org/10.1016/j.renene.2010.03.012

URL http://www.sciencedirect.com/science/article/pii/S0960148110001291

[23] G. B. Andresen, R. A. Rodriguez, S. Becker, M. Greiner, The potential for arbitrage of wind and solar surplus power in denmark, Energy 76 (0) (2014) 49 -58. doi:http://dx.doi.org/10.1016/j.energy. 2014.03 .033 .

URL http://www.sciencedirect.com/science/article/pii/S0360544214002977

[24] D. Heide, M. Greiner, L. von Bremen, C. Hoffmann, Reduced storage and balancing needs in a fully renewable European power system with excess wind and solar power generation, Renewable Energy 36 (9) (2011) 2515 - 2523. doi:http://dx.doi.org/10.1016/j.renene.2011.02.009

[25] S. Becker, R. Rodriguez, G. Andresen, S. Schramm, M. Greiner, Transmission grid extensions during the build-up of a fully renewable pan-european electricity supply, Energy 64 (2014) 404 - 418. doi: http://dx.doi.org/10.1016/j.energy.2013.10.010. URL http://www.sciencedirect.com/science/article/pii/S0360544213008438

26] R. A. Rodrguez, S. Becker, G. B. Andresen, D. Heide, M. Greiner, Transmission needs across a fully renewable european power system, Renewable Energy 63 (2014) 467 - 476. doi:http://dx.doi.org/ $10.1016 / j$.renene.2013.10.005

URL http://www.sciencedirect.com/science/article/pii/S0960148113005351 
[27] R. A. Rodriguez, M. Dahl, S. Becker, M. Greiner, Localized vs. synchronized exports across a highly

ㅁ renewable paneuropean transmission network, Energy, Sustainability and Society 5 (1) (2015) 1-9. doi: 10.1186/s13705-015-0048-6. URL http://dx.doi.org/10.1186/s13705-015-0048-6

[28] S. Becker, B. A. Frew, G. B. Andresen, T. Zeyer, S. Schramm, M. Greiner, M. Z. Jacobson, Features of a 1. fully renewable $\{\mathrm{US}\}$ electricity system: Optimized mixes of wind and solar $\{\mathrm{PV}\}$ and transmission grid extensions, Energy 72 (2014) 443 - 458. doi:http://dx.doi.org/10.1016/j.energy.2014.05.067. URL http://www.sciencedirect.com/science/article/pii/S0360544214006343

[29] D. Schlachtberger, S. Becker, S. Schramm, M. Greiner, Backup flexibility classes in emerging large-scale renewable electricity systems, Energy Conversion and Management (2016) doi:http://dx.doi.org/ $10.1016 / j$.enconman.2016.04.020

URL http://www.sciencedirect.com/science/article/pii/S0196890416302606

${ }_{480}^{4}[30]$ S. Suranjana, M. Shrinivas, P. Hua-Lu, W. Xingreni, W. Jiande, N. Sudhir, The NCEP Climate Forecast System Reanalysis, Bulletin of the American Meteorological Society 91 (8) (2010) 1015-57.

URL http://dx.doi.org/10.1175/2010BAMS3001.1

[31] S. Saha, S. Moorthi, X. Wu, J. Wang, S. Nadiga, P. Tripp, D. Behringer, Y.-T. Hou, H. ya Chuang, M. Iredell, M. Ek, J. Meng, R. Yang, M. P. Mendez, H. van den Dool, Q. Zhang, W. Wang, M. Chen, E. Becker, Ncep climate forecast system version 2 (cfsv2) selected hourly time-series products, Bulletin of the American Meteorological Society.

URL http://dx.doi.org/10.5065/D6N877VB

[32] S. Bofinger, L. von Bremen, K. knorr, K. lesch, K. Rohrig, Y.-M. Saint-Drenan, M. Speckmann, "raumzeitliche erzeugungsmuster von wind- und solarenergie in der ucte region und deren einfluss auf elektrische transportnetze.", Tech. rep., Institut fr Solare Energieversorgungstechnik, ISET e.V.; (November, 2008).

[33] H. C. Gils, J. Cofala, F. Wagner, W. Schpp, Gis-based assessment of the district heating potential in the \{USA\}, Energy 58 (2013) 318 - 329. doi:http://dx.doi.org/10.1016/j.energy.2013.06.028. URL http://www.sciencedirect.com/science/article/pii/S0360544213005264

[34] I.-A. Yeo, S.-H. Yoon, J.-J. Yee, Development of an urban energy demand forecasting system to support environmentally friendly urban planning, Applied Energy 110 (2013) $304-317$. doi:http://dx.doi. org/10.1016/j.apenergy.2013.04.065.

URL http://www.sciencedirect.com/science/article/pii/S0306261913003619

[35] S. Petrovic, K. Karlsson, Use of danish heat atlas and energy system models for exploring renewable energy scenarios, in: Proceedings of the 8th Conference on Sustainable Development of Energy, Water and Environment Systems (SDEWES 2013). 
[36] B. Moeller, S. Nielsen, High resolution heat atlases for demand and supply mapping, International a Journal of Sustainable Energy Planning and Management 1 (2014) 41-58. doi:10.5278/ijsepm. 2014. 1.4

URL https://journals.aau.dk/index.php/sepm/article/view/548

[37] K. N. Finney, J. Zhou, Q. Chen, X. Zhang, C. Chan, V. N. Sharifi, J. Swithenbank, A. Nolan, S. White, S. Ogden, R. Bradford, Modelling and mapping sustainable heating for cities, Applied Thermal Engineering 53 (2) (2013) 246 - 255, includes Special Issue: PRO-TEM Special Issue. doi:http://dx.doi.org/10.1016/j.applthermaleng.2012.04.009.

URL http://www.sciencedirect.com/science/article/pii/S1359431112002402

[38] U. Rasmussen, Water consumption in the energy sector and energy consumption in the water-sector in a danish municipality. Journal of Transdisciplinary Environmental Studies 11 (1) (2012) 3 - 5.

a URL http://search.ebscohost.com/login. aspx?direct=true\&db=eih\&AN=79201302\&site= ehost-live

[39] C. for International Earth Science Information Network (CIESIN) Columbia University, C. I. de Agricultura Tropical (CIAT), Gridded population of the world, version 3 (gpwv3): Population density grid, future estimates (20160603 2005).

URL http://dx.doi.org/10.7927/H4ST7MRB

[40] R. A. Cox, M. Drews, C. Rode, S. B. Nielsen, Simple future weather files for estimating heating and cooling demand, Building and Environment 83 (2015) 104 - 114, special Issue: Climate adaptation in cities. doi:http://dx.doi.org/10.1016/j.buildenv.2014.04.006.

URL http://www.sciencedirect.com/science/article/pii/S0360132314001024

[41] L. Pedersen, J. Stang, R. Ulseth, Load prediction method for heat and electricity demand in buildings for the purpose of planning for mixed energy distribution systems, Energy and Buildings 40 (7) (2008) 1124 - 1134. doi:http://dx.doi.org/10.1016/j.enbuild.2007.10.014. URL http://www.sciencedirect.com/science/article/pii/S0378778807002381

[42] R. Burzynski, M. Crane, R. Yao, V. M. Becerra, Space heating and hot water demand analysis of dwellings connected to district heating scheme in uk, Journal of Central South University 19 (6) (2012) 1629-1638. doi:10.1007/s11771-012-1186-z.

URL http://dx.doi.org/10.1007/s11771-012-1186-z

[43] K. Papakostas, T. Mavromatis, N. Kyriakis, Impact of the ambient temperature rise on the energy consumption for heating and cooling in residential buildings of greece, Renewable Energy 35 (7) (2010) 1376 - 1379, special Section: \{IST\} National Conference 2009. doi:http://dx.doi.org/10.1016/j. renene.2009.11.012.

URL http://www.sciencedirect.com/science/article/pii/S0960148109004881 
[52] J. Hadorn, Solar and Heat Pump Systems for Residential Buildings, Solar Heating and Cooling, Wiley, 2015.

[55] A. Hberle, M. D. Moldovan, I. Visa, M. Neagoe, B. G. Burduhos, Solar heating \& cooling energy mixes to transform low energy buildings in nearly zero energy buildings, Energy Procedia 48 (2014) $924-937$. doi:http://dx.doi.org/10.1016/j.egypro.2014.02.106

URL http://www.sciencedirect.com/science/article/pii/S1876610214003683 